\title{
Effect of the Different Crystallinity of Ionic Liquid Based Solid Polymer Electrolyte on the Performance of Amperometric Gas Sensor ${ }^{+}$
}

\author{
Petr Sedlák 1,*, Petr Kuberský ${ }^{2}$, Adam Gajdoš ${ }^{1}$, Jiří Majzner 1, Vlasta Sedláková ${ }^{1}$, \\ Robert Macků ${ }^{1}$ and Vladimír Holcman ${ }^{1}$ \\ 1 Faculty of Electrical Engineering and Communications, Brno University of Technology, Technická 10, \\ 61600 Brno, Czech Republic; \\ 2 Regional Innovation Centre for Electric Engineering, Faculty of Electrical Engineering, University of West \\ Bohemia, Univerzitni 8, 30100 Plzen, Czech Republic; kubersky@ket.zcu.cz \\ * Correspondence: sedlakp@feec.vutbr.cz; Tel.: +420-541-146-021 \\ + Presented at the 7th International Electronic Conference on Sensors and Applications, 15-30 November \\ 2020. Available online: https://ecsa-7.sciforum.net/.
}

Published: 15 November 2020

\begin{abstract}
Solid polymer electrolytes (SPE) based-on ionic liquid, poly-(vinylidene fluoride) and solvent N-methyl-pyrrolidone represent the effective component in electrochemical sensors. The advantage lays in the composition, which offers an opportunity to prepare SPE layers with different porosity and microstructure. The study shows how SPE of different crystallinity affects the performance of amperometric gas sensor from the point of view of current response (sensitivity), limit of detection and current fluctuations. The morphology of SPE has impact not only on its conductivity but also on sensor sensitivity due to morphology of the interface SPE/working electrode (WE).
\end{abstract}

Keywords: electrochemical sensor; ionic liquid; solid polymer electrolyte; crystallinity; sensitivity; fluctuations; noise; limit of detection

\section{Introduction}

Disadvantages of classical liquid electrolytes are overcome by usage solid polymer electrolyte (SPE) which is usually based on organic ionic liquid immobilized in polymer matrix. Ionic liquids are currently widely used in various fields of electrochemistry and chemistry because of their unique properties, which are partially implemented in SPE [1]. SPEs are considered as suitable type of materials for printed or flexible electronics [2,3]. Need to note, SPE-based gas sensors may exhibit a systematic drawback such as poor stability, low selectivity, short lifetimes etc. [4-6]. Thus, the researchers are well-motivated in the development of SPE for sensing applications.

The study focuses on the SPE which consists of three basic components: (i) ionic liquid, (ii) poly(vinylidene fluoride) (PVDF), (iii) N-methyl-pyrrolidone (NMP) as a solvent. The great advantage of this type SPE is the fact that its composition offers an opportunity to prepare SPE layers with different porosity and microstructure. The temperature has a strong impact on the type of crystalline phase of the polymer (PVDF) in the solvent (NMP) [7]. Further a specific crystalline phase ( $\alpha$ phase or $\beta$ phase) of the PVDF in NMP of the SPE layer has an evident impact on sensor characteristic[8,9]. The sensor sensitivity depends not only on the type of WE material but also on the morphology of the electrochemical active interface SPE/WE and therefore on the thermal treatment conditions of the deposited SPE layer [8]. Our study shows how SPE of different crystallinity affects the performance of amperometric gas sensor from the point of view of current response (sensitivity), limit of detection 
and current fluctuations. This work follows up on our paper [10] where we studied the influence of three different technologies on current fluctuations in the amperometric gas sensor.

\section{Sensor Preparation and Experimental Setup}

Figure 1a presents the semi-planar three electrode topology on which experimental study was carried out. The ceramic substrate with platinum electrodes was customized in TESLA Blatná Company (Czech Republic). Before preparation, the sensor elements were properly sonicated in a cleaning bath and subsequently thoroughly washed in deionized water. Thereafter, the layer of solid polymer electrolyte (SPE) consisting of 1-butyl-1-methylpyrrolidinium bis(trifluoromethylsulfonyl)imide[BMPYR][N(Tf)2], poly(vinylidene fluoride), and 1-methyl-2pyrrolidone was deposited by drop casting technique. After the deposition, the alumina substrate with the SPE layer was placed on a hot plate where the sample was kept at an appropriate temperature for a specific time in order to achieve different crystalline forms of the polymer in the solvent. The conditions for preparation of SPE were (i) $90{ }^{\circ} \mathrm{C} 1.5 \mathrm{~min}$, (ii) $120{ }^{\circ} \mathrm{C} 1.5 \mathrm{~min}$, (iii) $120{ }^{\circ} \mathrm{C}$ $3.5 \mathrm{~min}$ and (iv) $160^{\circ} \mathrm{C} 10 \mathrm{~min}$. The working electrode was deposited by airbrushing of spherical glassy carbon powder. Figure $1 \mathrm{~b}-\mathrm{d}$ ) illustrates the morphology of the interface between (glassy carbon) working electrode and SPE at three different magnifications. Further details about the sensor platform and SPE preparation can be found in Ref.[11] and Ref.[9,12], respectively.
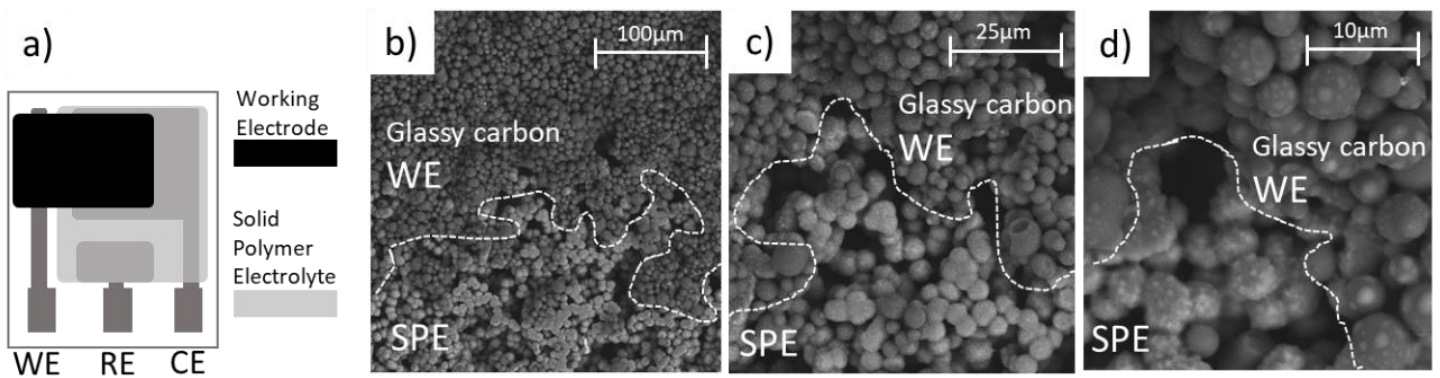

Figure 1. (a) Sensor topology, (b-d) the morphology of the working electrode/solid polymer electrolyte at three different magnifications.

Each type of sensor was exposed to $\mathrm{NO}_{2}$ concentration ranging from $0 \mathrm{ppm}$ up to $10 \mathrm{ppm}$ in the conditions of flow rate $1 \mathrm{~L} / \mathrm{min}, 298 \mathrm{~K}, 40 \% \mathrm{RH}$ in a test chamber. The exact concentrations were set by the apparatus (described in [13]) which consisted of PC-controlled mass flow controllers, gas cylinders with synthetic air and a reference calibration mixture (100 ppm NO2 balanced in nitrogen). The particular sensor was a part of potentiostat circuit based on a rail-to-rail operational amplifier (OPA2144-Texas Instruments), in grounded-WE configuration. The potentiostat circuit and low noise transimpedance amplifier were implemented into one device [13], which gives us the possibility to measure current fluctuation as well as DC current at the same time. The AC voltage output was led to an amplifier with highly selective filters AM22 (3S Sedlak, s.r.o.), and was obtained by a 12-bit AD convertor HS6 (TiePie engineering) as well as DC voltage output.

\section{Results and Discussion}

All electrical measurements were provided under equilibrium conditions when the sensor was being kept at particular concentration for the required amount of time to fulfill the memorylessness of current fluctuations. The DC current via a sensor was measured and monitored until it did not change its mean value for $100 \mathrm{~s}$. After this (approximately $300 \mathrm{~s}$ from the beginning), we ran the current fluctuation measurement with a DC current measurement at the same time. Figure 2a shows the dependences of DC current on concentration, where the highest DC response corresponds to the SPE of the highest temperature and the longest interval of treatment after deposition. As concentration increases, the DC component linearly increases for all orientations. According to our investigations [14] the ionic conductivity was found to increase with increasing crystallization 
temperature. The surface of SPE consists of very small spherical SPE objects whose diameter increases with crystallization temperature, thus the lower value of this temperature results in higher porosity of prepared SPE. Need to note that we were not able to find any spherical object on surfaces of the SPE samples based on [BMPYR][N(Tf)2] which were prepared at conditions $10 \mathrm{~min}$ at $160{ }^{\circ} \mathrm{C}$ [14].
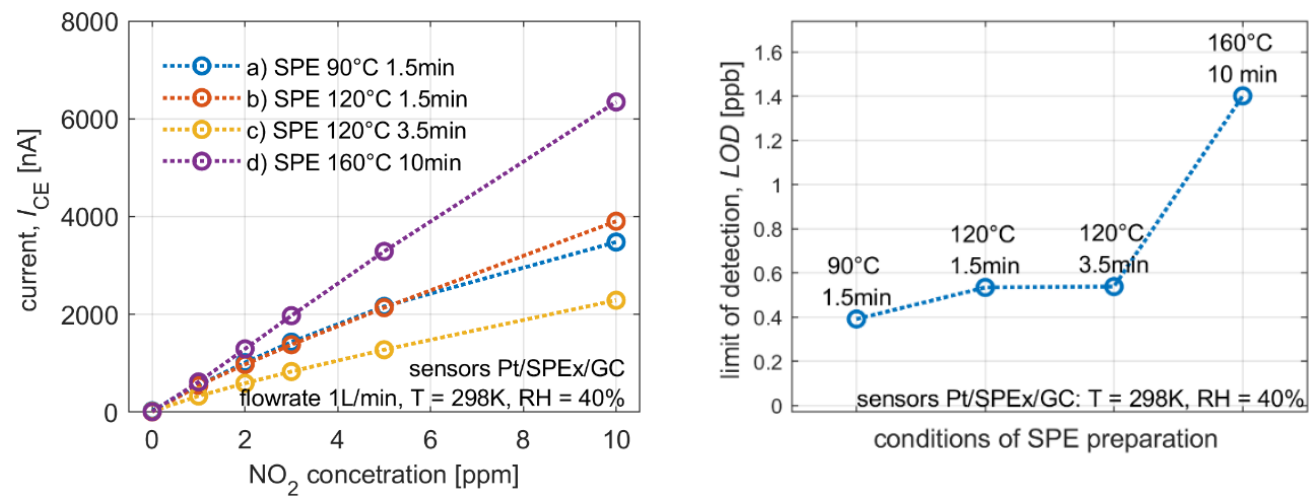

Figure 2. (a) dependences of DC current on $\mathrm{NO}_{2}$ concentrations and (b) limit of detection for four sensors of different SPE processed by different treatment conditions.

The limit of detection (LOD) is introduced as the ratio of the triple standard deviation of the background current noise (at zero concentration) and sensitivity (dc current pre ppm). LOD is a rather theoretical value that can be usually verified with difficulty, but this sensor parameter helps to describe the overall performance and is worth determining. Figure $2 b$ illustrates how LOD depends on conditions of SPE treatment. Need to note that the sensor of the highest DC response (sensitivity) exhibit the worst LOD value.

Figure 3 shows spectral densities of current fluctuations depending on $\mathrm{NO}_{2}$ concentrations as the SPEs of sensors were prepared under different treatment conditions. At zero concentration, power spectra exhibit thermal noise, which is associated with all dissipative processes across the sensor and corresponds to real part of electrical impedance of the sensor, and, either $f^{-1.25}$ noise component, which should indicate diffusion-dominant electrode electrolyte interface [13,15-17], or $f^{2.00}$ noise component, which should indicate drift-dominant electrode electrolyte interface [15]. The differences in these power spectra is given by different crystallinity of SPE, since SPE conductivity increases with the crystallization temperature [14] and morphology of electrode/electrolyte interface develops as SPE porosity decreases with the crystallization temperature. At higher $\mathrm{NO}_{2}$ concentrations, the spectral densities of current fluctuations contain (i) noise component of Lorentzian-a-like spectra assumed to be the result of several mutually influencing stochastic processes [13], (ii) the noise component $f^{2}$, indicating adsorption-desorption noise or drift-dominant electrode/electrolyte interface [15], and (iii) thermal noise, which increases due to a change of sensor capacity. The sensor with the SPE of the highest temperature and the longest interval of treatment after deposition showed the highest current fluctuations in the frequency range.
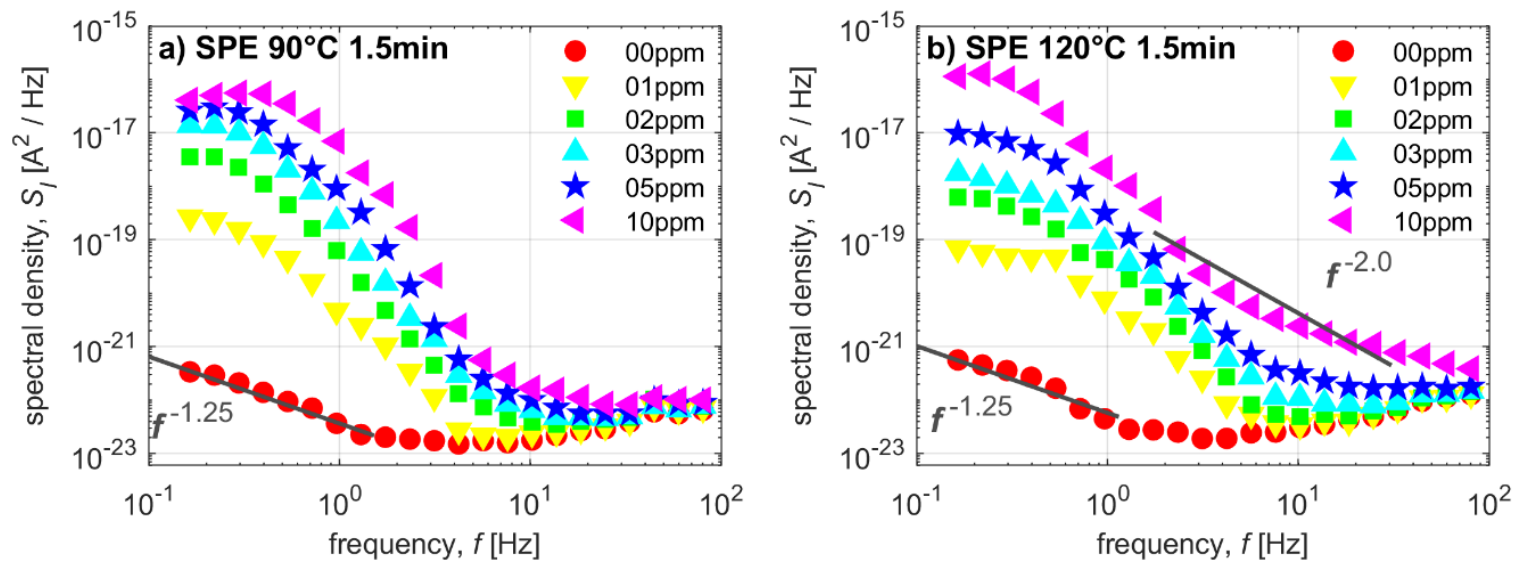

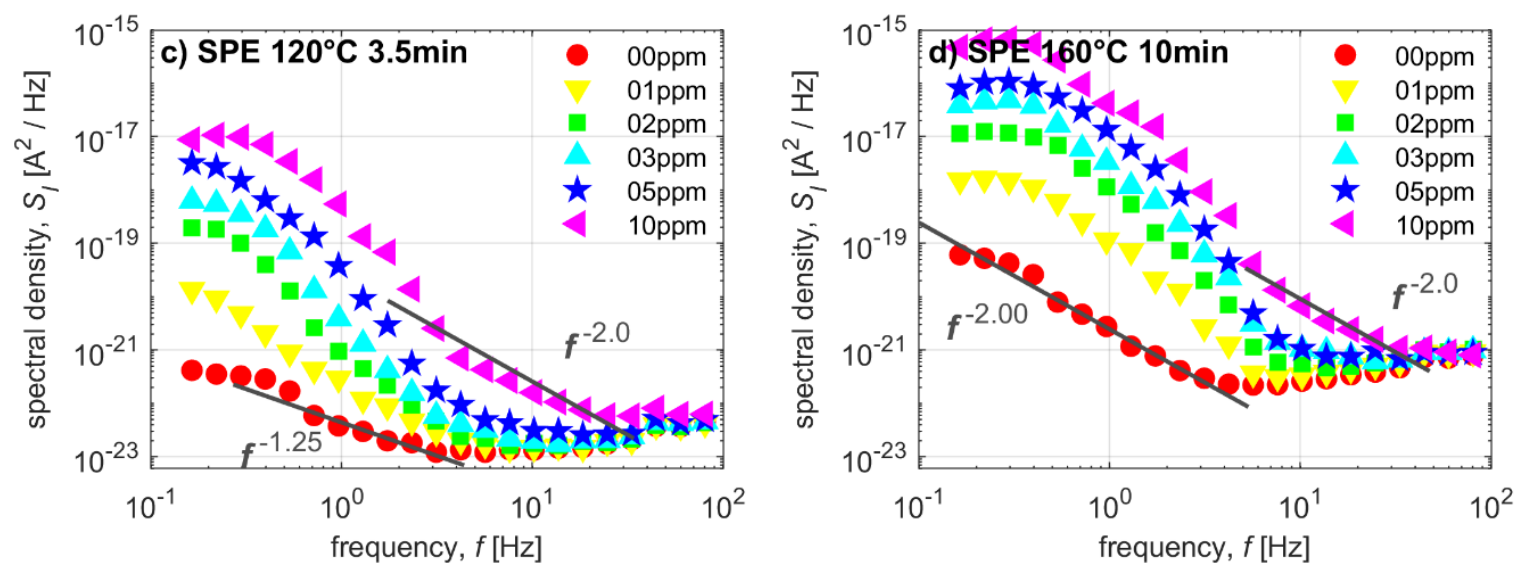

Figure 3. Spectral densities of current fluctuations depending on $\mathrm{NO}_{2}$ concentrations for the frequency range from $0.1 \mathrm{~Hz}$ up to $100 \mathrm{~Hz}$ for the sensors with SPE prepared at conditions (a) $90{ }^{\circ} \mathrm{C} 1.5 \mathrm{~min}$, (b) $120^{\circ} \mathrm{C} 1.5 \mathrm{~min},(\mathbf{c}) 120^{\circ} \mathrm{C} 3.5 \mathrm{~min},(\mathrm{~d}) 160{ }^{\circ} \mathrm{C} 10 \mathrm{~min}$.

\section{Conclusions}

The contribution showed and discussed the effect of the different crystallinity of ionic liquid based solid polymer electrolyte on the performance of amperometric gas sensor. The results show that thermal treatment for ionic liquid based SPE impact the overall performance of the sensor. The higher rate of solvent evaporation due to thermal treatment leads to change morphological change as well as change of ionic conductivity of SPEs. This results in the increase of sensor sensitivity and also current noise. The level of noise background is contra-productively high while the limit of detection is very low in comparison with other variants of SPE treatment that have less current response to the concentration of the detected substance.

Author Contributions: P.S. together with P.K. initiated the research. P.S. designed of noise measurements, evaluated current fluctuations and prepared the text. P.K. prepared sensors, designed the experiment (sensor properties), and revised the text. A.G. provided SEM analyses of different SPE and an interface of WE/SPE. J.M. designed the measurement setup for dielectric spectroscopy. V.S. revised the text and together with V.H. evaluated the conductivity of SPE with different crystallinity. R.M. participated on design of noise measurements. All authors have read and agreed to the published version of the manuscript.

Funding: Research described in this paper was by the grant 18 19104S of the Czech Science Foundation (GACR).

Conflicts of Interest: The authors declare no conflict of interest.

\section{References}

1. Singh, V.V.; Nigam, A.K.; Batra, A.; Boopathi, M.; Singh, B.; Vijayaraghavan, R. Applications of Ionic Liquids in Electrochemical Sensors and Biosensors. Int. J. Electrochem. 2012, 2012, 165683.

2. Vonau, C.; Zosel, J.; Paramasivam, M.; Ahlborn, K.; Gerlach, F.; Vashook, V.; Guth, U. Polymer based materials for solid electrolyte sensors. In Proceedings of the Solid State Ionics; Elsevier: 2012; Volume 225, pp. 337-341.

3. Correia, D.M.; Fernandes, L.C.; Martins, P.M.; García-Astrain, C.; Costa, C.M.; Reguera, J.; LancerosMéndez, S. Ionic Liquid-Polymer Composites: A New Platform for Multifunctional Applications. Adv. Funct. Mater. 2020, 30, 1909736.

4. Korotcenkov, G.; Cho, B.K. Instability of metal oxide-based conductometric gas sensors and approaches to stability improvement (short survey). Sens. Actuators B Chem. 2011, 156, 527-538.

5. Luo, R.; Li, H.; Du, B.; Zhou, S.; Chen, Y. A printed and flexible $\mathrm{NO}_{2}$ sensor based on a solid polymer electrolyte. Front. Chem. 2019, 7, 286.

6. Luo, R.; Li, Q.; Du, B.; Zhou, S.; Chen, Y. Preparation and Characterization of Solid Electrolyte Doped with Carbon Nanotubes and its Preliminary Application in $\mathrm{NO}_{2}$ Gas Sensors. Front. Mater. 2019, 6, 113.

7. Gregorio, R.; Borges, D.S. Effect of crystallization rate on the formation of the polymorphs of solution cast poly(vinylidene fluoride). Polymer 2008, 49, 4009-4016.

8. Nespurek, S.; Mracek, L.; Kubersky, P.; Syrovy, T.; Hamacek, A. Ionic liquids in electrochemical gas sensors 
and transistors. Mol. Cryst. Liq. Cryst. 2020, 694, 1-20.

9. Kuberský, P.; Altšmíd, J.; Hamáček, A.; Nešpůrek, S.; Zmeškal, O. An electrochemical NO2 sensor based on ionic liquid: Influence of the morphology of the polymer electrolyte on sensor sensitivity. Sensors 2015, 15, 28421-28434.

10. Sedlak, P.; Kubersky, P.; Skarvada, P.; Hamacek, A.; Sedlakova, V.; Majzner, J.; Nespurek, S.; Sikula, J. Current Fluctuation Measurements of Amperometric Gas Sensors Constructed with Three Different Technology Procedures. Metrol. Meas. Syst. 2016, 23, 531-543.

11. Kuberský, P.; Hamáček, A.; Nešpůrek, S.; Soukup, R.; Vik, R. Effect of the geometry of a working electrode on the behavior of a planar amperometric NO2 sensor based on solid polymer electrolyte. Sens. Actuators B Chem. 2013, 187, 546-552.

12. Kuberský, P.; Syrový, T.; Hamáček, A.; Nešpůrek, S.; Syrová, L. Towards a fully printed electrochemical NO2 sensor on a flexible substrate using ionic liquid based polymer electrolyte. Sens. Actuators B Chem. 2015, 209, 1084-1090.

13. Sedlák, P.; Kuberský, P.; Mívalt, F. Effect of various flow rate on current fluctuations of amperometric gas sensors. Sens. Actuators B Chem. 2019, 283, 321-328.

14. Sedlak, P.; Gajdos, A.; Macku, R.; Majzner, J.; Sedlakova, V.; Holcman, V.; Kuberský, P. The effect of thermal treatment on ac/dc conductivity and current fluctuations of PVDF/NMP/[EMIM][TFSI] solid polymer electrolyte. Sci. Rep.

15. Hassibi, A.; Navid, R.; Dutton, R.W.; Lee, T.H. Comprehensive study of noise processes in electrode electrolyte interfaces. J. Appl. Phys. 2004, 96, 1074-1082.

16. Sedlák, P.; Kuberský, P. The Effect of the Orientation Towards Analyte Flow on Electrochemical Sensor Performance and Current Fluctuations. Sensors 2020, 20, 1038.

17. Kuberský, P.; Sedlák, P.; Hamáček, A.; Nešpůrek, S.; Kuparowitz, T.; Šikula, J.; Majzner, J.; Sedlaková, V.; Grmela, L.; Syrový, T. Quantitative fluctuation-enhanced sensing in amperometric $\mathrm{NO}_{2}$ sensors. Chem. Phys. 2015, 456 .

Publisher's Note: MDPI stays neutral with regard to jurisdictional claims in published maps and institutional affiliations.

(C) 2020 by the authors. Licensee MDPI, Basel, Switzerland. This article is an open access article distributed under the terms and conditions of the Creative Commons Attribution (CC BY) license (http://creativecommons.org/licenses/by/4.0/). 